\title{
Erasmo, Rabelais y Brantôme, dos rostros del libertinismo y el libertinaje del siglo XVI
}

\author{
Claudia RUIZ GARCÍA \\ Universidad Nacional Autónoma de México
}

Asociar en estas líneas a François Rabelais y a Pierre de Bourdeille, mejor conocido como el abad de Brantôme, o simple y llanamente como Brantôme, autor de los Sermens et juremens espaignoles, las Rodomontades espaignoles y Les Vies des Dames Galantes, entre otros títulos, resulta una tarea que conlleva por lo menos dos riesgos.

El primero de ellos consiste en definir el binomio de términos - libertinismo y libertinaje - que justificaría reunirlos aquí, y el segundo reside en que para aproximarse a Brantôme a veces es mucho más atractivo hacerlo no tanto como teólogo o filósofo, que no lo es, sino más bien como una especie de sociólogo, muy particular, concentrado en hablar de las prácticas sexuales de las mujeres de cierto rango social.

Si nos detuviéramos un momento en el primer riesgo mencionado habría que reconocer que existe una vasta bibliografía (véase Jean Claude Margolin, 1974) interesada en ceñir los diferentes matices semánticos que estos términos poseen durante el siglo XVI. Baste, para nuestro propósito, recordar que estas palabras están vinculadas con una más - libertin- que se incorpora a la lengua francesa por primera vez en un tratado redactado por Calvino, a mediados de ese siglo, intitulado Brieve Instruction pour armer tous bons fideles contre les erreurs de la secte commune des Anabaptistes. Este estudio semántico permite desentrañar un problema mucho más amplio asociado a cuestiones que tienen que ver con el estudio de la mentalidad de la época, su sicología social, sus costumbres, al igual que la historia de la filosofía y sobre todo la historia de las prácticas religiosas del momento. Así, se asignará la voz libertino a todo aquel que por su manera de ser, juzgar o sentir será percibido como un adversario de una postura religiosa de la gran mayoría. Dentro de esta categoría cabe muy bien revisar los puntos de vista de los autores referidos porque, de alguna forma, su manera de decir las cosas resultará un tanto incómoda y agresiva para ciertos sectores de la sociedad de la época. 
Empecemos por Rabelais, considerado por algunos de sus contemporáneos como un simple monje défroqué, que llegó más tarde a ser un médico mediocre o como lo ha visto uno de los más importantes estudiosos de su obra, Michael Screech, quien en su libro Rabelais lo sitúa como un hombre enrolado en uno de los juegos más serios, pues el análisis que hace de su época no lo realiza por ataques brutales contra los prejuicios del momento, sino más bien mediante críticas jocosas que buscan restablecer la armonía y la razón de su entorno. Sólo nos limitaremos a repasar una de sus obras -Gargantua - pues de ella se desprende una serie de reflexiones ligadas a las preocupaciones que nos interesa hacer resaltar aquí, para poder entender la razón por la cual se le puede clasificar como un partidario del libertinismo del Renacimiento francés.

En primer lugar hay que reconocer que Rabelais está inscrito dentro de una tradición humanista cuyo primer propósito consiste en sacudir las conciencias dormidas de su época. Uno de sus principales guías es Luciano de Samosata, autor de la Historia verdadera, y reconocido por Calvino como el maestro de todos los ateos de su tiempo. Esta opinión tendría que usarse con mucha cautela, pues el término "ateo" a lo largo del siglo XVI no logra todavía precisarse. Calvino, en la Institution de la Religion Chrétienne, critica al papado señalando:

Dieu sait quels vicaires du Christ nous trouverons, et tout le monde le cognoit... Nous savons qu'ils n'ont jamais rien tenu de Jésus-Christ, sinon ce qu'ils en avaient appris en l'escole de Lucien... Le premier article de leur théologie, laquelle ils ont entre eux, est qu'il n'y a point de Dieu. Le second, que tout ce qui est écrit et tout ce qu'on presche de Jésus-Christ n'est que mensonge et abus. Le troisième, que tout ce qui est contenu dans l'Éscriture touchant à la vie éternelle et la résurrection de la chair n'est que fable (C. Lavergnat-Garnière 1978: 70-71). ${ }^{1}$

Con esta observación, aunada a la opinión que se tiene de Luciano como el escritor que supo hacer una caricatura de cosas serias, se ha podido reconocer que Rabelais retomó algunos motivos y sobre todo el tono de los es-

${ }^{1}$ Dios sabe qué vicarios de Cristo encontraremos y todo el mundo lo conoce... Sabemos que no tienen nada de Jesucristo, sino lo que habían aprendido en la escuela de Luciano... El primer artículo de su teología, la que manejan entre ellos, es que no hay Dios. El segundo, que todo lo que está escrito y todo lo que ha predicado Jesucristo no es más que una mentira y abuso. El tercero, que todo lo que contiene la Escritura referente a la vida eterna y la resurrección de la carne no es más que una fábula. (Todas las traducciones son mías con excepción de los textos citados por Rabelais.) 
critos de Luciano, a quien descubrió cuando aprendió griego, traduciendo posteriormente una buena parte de sus textos. Sin embargo, Rabelais no es el primero en empaparse de la técnica utilizada por Luciano. Tomás Moro y, sobre todo, Erasmo de Rotterdam, quien también se ocupó de traducir la obra luciana, lo habían hecho anteriormente. Interesa detenerse en este último porque, aunque sus libros no se caractericen por la ambigüedad que sí encontramos en Rabelais, sus escritos filosóficos-teológicos fueron condenados por la Sorbona a partir de 1526, lo que no sucedió con los textos de Rabelais. Esta situación no deja de asombrar pues en la obra rabelesiana se recogen varios ecos de algunas voces que Erasmo había vertido en sus $C o$ loquios y en el Elogio de la locura.

Conocida es la polémica vida del humanista holandés, figura precursora de la Reforma de la Iglesia, junto con otro de sus compatriotas como Tomás a Kempis. Se trata de un hombre convencido de que la verdadera piedad no debe limitarse a una serie de prácticas rutinarias como los ayunos, los rezos y los ritos que la Iglesia ordena realizar. Para él la auténtica devoción queda asentada en el feligrés cuando éste logra mantener una comunicación directa y un fuerte sentimiento de confianza y de amor hacia Jesucristo. Para Erasmo sólo de esta forma el cristiano logra salvarse de la desdicha, el castigo y la muerte. Esta postura es compartida a medias - sobre todo en lo que se refiere a la vacuidad de las prácticas de devoción- por Lutero. Sin embargo, Erasmo siempre mantuvo, con respecto a la visión reformista del monje alemán, un enorme recelo. Incluso, presionado por los papas Adrián IV y León X, así como por el rey Enrique VIII, tomó posición contra el monje agustino en relación con su tesis defendida acerca de la predestinación. Algunos reformistas criticaron esta situación, acusándolo de aceptar una clara sumisión a las autoridades de la Iglesia de Roma, solapando con ello una multiplicidad de costumbres viciosas en el seno de ella. Hay que recordar que no son únicamente los reformistas quienes ponen en tela de juicio sus actitudes y opiniones. También, del otro lado del frente, los católicos le reprocharon las críticas que Erasmo hizo de la Vulgata, que algunos consideraban como un texto inspirado, además de las acusaciones lanzadas contra la Iglesia por quemar a los herejes, pervirtiendo y violando ciertos puntos de las enseñanzas de Cristo. Por todo esto y más Erasmo reúne una parte del perfil de lo que ha dado por denominarse "libertino" en esa época, pues el término conlleva asumir una actitud crítica y sistemática de la tradición religiosa. Tal vez, podría imaginarse que uno de los propósitos de Erasmo hubiera sido reducir el cristianismo a una simple moral. Su libertinismo, que será también el de Rabelais, se orienta hacia varias direcciones. En primer lugar hacia la sátira del clero; después hacia la crítica de 
la devoción tradicional. Finalmente, también podría observarse una fracción de libertinismo, que algunos percibieron como manifestaciones de franca herejía, cuando Erasmo interpreta o parafrasea las Escrituras con cierta óptica aguda que fue más bien entendida como insolente e irrespetuosa. Y es indiscutible que su irreverencia anuncia el tono burlón que encontraremos en algunos escritos libertinos de los siglos XVII y XVIII, pero que no mencionaremos aquí por escapar a nuestros propósitos. Lo que podemos señalar es que la crítica que hace de cada una de las orientaciones mencionadas revela una cierta libertad de opinión que, aunque más tarde le valga el repudio de grandes sectores, defensores de cualquier tipo de ortodoxia, resume una gran parte de las inquietudes de varios de sus contemporáneos por renovar la espiritualidad y asentar así lo que ha dado por llamarse la devoción moderna. Veamos algunos casos concretos.

A Erasmo se le reprochó el haber apuntalado una parte de sus críticas mordaces a la devoción de los santos. Sin embargo, en ninguno de sus escritos se encuentra la reprobación de este tipo de culto, sino más bien su denuncia de la superstición generalizada en los fieles, cuya forma de preservar los hábitos de oración permite reconocer en dichas prácticas religiosas algunas reminiscencias de paganismo. Erasmo considera inútil invocar en plegarias a una serie de intermediarios cuando la lógica pediría dirigirse directamente a Dios. Esta misma preocupación se hace patente en Rabelais. En Gargantua encontramos un ejemplo de ello en el capítulo XXVII, que cuenta la historia del saqueo del huerto de la abadía. Las víctimas de esta agresión, en su afán de sentir alguna protección, invocan hasta los santos menos conocidos o imaginarios. En este episodio observamos a las víctimas en medio de la desesperación:

Les uns cryoient: Sainte Barbe!

Les aultres: Sainct George!

Les aultres: Saincte Nytouche!

Les aultres: Nostre Dame de Cunault! de Laurette! de Bonnes Nouvelles! de la Lenou! de Rivière!

Les ungs se vouoyent à sainct Jacques;

les aultres au sainct suaire de Chambéry, mais il brusla troys moys après, si bien qu'on n'en peut saulver un seul brin;

les aultres à Cadouyn;

les aultres à sainct Jean d'Angéry;

les aultres à sainct Eutrope de Xainctes, à sainct Mesmes de Chinon, à sainct Martin de Candes, à sainct Clouaud de Sinays, ès reliques de Javrezay et mille aultres bon petitz saincts.

Les ungs mouroient sans parler, les aultres parloient sans mourir, les 
ungs mouroient en parlant, les aultres parloient en mourant. Les aultres crioient à haulte voix: "Confession ${ }_{i}$ Confession $;$ Confetior Miserere ${ }_{i}$ In manus $\mathrm{i}$ (ed. de Jacques Boulenger 1951: 108-109). ${ }^{2}$

Un episodio muy similar está presente en Pantagruel. En un pasaje que refiere la llegada de una tempestad, Panurge invoca a santos como Miguel de Aure o san Nicolás, además de implorar la confesión y la bendición. Pantagruel, por el contrario, se limita únicamente a formular una oración en la que asume la decisión de la voluntad divina. En ambos textos hemos visto que siempre aparece la preocupación por confesarse en un momento en que el peligro de muerte es inminente. Rabelais, burlándose de esta tendencia que con frecuencia se observa en la naturaleza humana, la vuelve a plantear en el capítulo XLII, en el que Gargantua encuentra a un monje colgado de un árbol por un accidente ocurrido en el momento en que cabalgaba hacia un saucedal. Este monje solicita auxilio diciendo:

Aidez-moy, de par le diable! N'est-il pas bien le temps de jazer? Vous me semblez les prescheurs décretalistes, qui disent que quiconques voira son prochain en dangier de mort, il le doibt, sus peine d'excommunication trisulce, plustoust asmonnester de soy confesser et mettre en estat de grâce que de luy ayder. Quand doncques je les voiray tombéz en la rivière et prestz d'estre noyez, en lieu de les aller querir et bailler la main, je leur feray un beau et long sermon de Contemptu mundi et fuga seculi, et, lorsqu'ilz seront roides mors, je les iray pescher.

-Ne bouge, dit Gymnasti, mon mignon, je te voys querir, car tu es gentil petit monachus:

monachus in claustro

non valet ova duo;

sed, quando est extra,

Bene valet trigenta (ed. de Jacques Boulenger 1951: 145-146). ${ }^{3}$

${ }^{2}$ Unos gritaban: ¡Santa Bárbara! Otros: ¡San Jorge! Otros: ¡Santa Nitouche! Otros: ¡Nuestra Señora de Cunault! ¡Nuestra Señora de Loreto! ¡Nuestra Señora de la Buena Nueva! ¡Nuestra Señora de Lenou! ¡Nuestra Señora de Rivière! Unos se encomendaban al apóstol Santiago; otros al Santo Sudario de Chambéry; que se quemó tres meses después, y no se pudo salvar nada de él, otros a Cadouin, otros a San Juan de Angely, otros a San Eutropio de Saintes a San Mesme de Chinon, a San Martín de Candes, a San Clouaud de Cinais, a las reliquias de Javarzay, y a otros mil santos más. Unos morían sin hablar, otros hablaban sin morir, unos morían hablando, otros hablaban muriendo. Otros gritaba: - ¡Confesión! ¡Confesión! Confetior, miserere, in manus. Versión de Juan G. de Luaces. Pp. 98-99.

${ }^{3}$ ¡Socorredme, por todos los diablos! — gritó el monje—. ¿Es éste el momento de 
Reconocemos en esta última observación una de las ideas más defendidas por Erasmo sobre la vida de los monasterios. Conocida es su frase monachatus non est pietas que cimbró de alguna forma a la Iglesia, pues cuestionó una de las prácticas comunes de muchas órdenes religiosas de la época: el encierro. Erasmo vivió en carne propia los horrores de la vida monástica y contra ella se rebeló, delatando la crueldad y la barbarie de ciertos métodos impuestos en esos lugares para comer, dormir, orar y aprender lecciones de teología y filosofía. Su dolorosa experiencia en el Collège de Montaigu ha sido recogida por la mayoría de sus biógrafos. Rabelais, por su parte, no desaprovecha ninguna oportunidad para hacer también un retrato feroz de la suciedad que imperaba en esta institución. Veamos lo que señala en el capítulo "De cómo Gargantúa, al peinarse, hacía caer de sus cabellos balas de artillería":

Ce que voyant, Grandgousier, son père, pensoit que feussent pous et luy dist: "Dea, mon filzs, nous as-tu aporté jusques icy des espaniers de Montagu?

Je entendois que là tu feisse résidence!

Adonc Ponocrates respondit:

'Seigneur, ne pensez que je l'aye mis au colliège de pouillerie qu'on nomme Montagu. Mieulx le eusse voulu mettre entre les guenaux de Sainct Innocent, pour l'énorme cruaulté et villennie que je y ay congneu. Car trop mieulx sont traictéz les forcéz entre les Maures et Tartares, les meurtrieus en la prison criminelle, voyre certes les chiens en vostre maison, que ne sont ces malantruz au dict colliège, et, si j'estois roy de Paris le diable m'emport si je ne metoys le feu dedans et faisois brusler et principal et régens qui endurent ceste inhumanité davant leurs yeulx estre exercée" (ed. de Jacques Boulenger 1951: $131-132){ }^{4}$

parlotear? Me parecéis predicadores decretalistas, que dicen que quienquiera que vea a su prójimo en peligro de muerte, debe, so pena de excomunión trifulca, exhortarle a confesarse y ponerse en estado de gracia antes de socorrerle. Como yo los viera caídos en el río y a punto de ahogarse, en vez de ir a buscarlos y tenderles la mano, les pronunciaría un bello y largo sermón sobre El desprecio del mundo y la huida del siglo y cuando estuvieran bien muertos, iría a pescarlos.

-No te muevas, querido - dijo Gimnasta-, que voy a descolgarte, porque eres un gentil frailecillo.

El fraile en el claustro

No vale dos huevos,

Pero cuando está fuera

Bien vale treinta. Pp. 137-138.

${ }^{4}$ Grandgousier, su padre, al verlo, creyendo que fueran piojos le dijo: 
Uno de los problemas que más preocupan a Rabelais es el estado del sistema monástico que, en su opinión, no tiene nada que ver con la religión de Cristo. Esta postura fue compartida por una gran mayoría de humanistas, quienes detestaban este tipo de prácticas, pues las consideraban más bien como simples tradiciones humanas que algunos intentaban disfrazar para hacerlas pasar como la verdadera sustancia de la religión. Aquí habría forzosamente que mencionar el episodio de la abadía de Thélème, en el que Rabelais nos presenta un lugar, no de encierro, sino de encuentro y convivencia común, donde hombres y mujeres daban libre curso al uso de su voluntad. Michael Screech (1992: 251) advierte que un gran número de prácticas tradicionales de la Iglesia —en particular en la vida monástica_eran consideradas por algunos como trampas de un neojudaismo que conllevaban una pérdida de la libertad del hombre concedida por Cristo. Rabelais comparte esta opinión. Así, observamos en el pasaje de Thélème un trastocamiento de las tres virtudes monásticas. La pobreza es remplazada por la riqueza, pues se trata de un lugar que cuenta con fuentes, bibliotecas de lujo, jardines, etcétera. La castidad, entendida como el celibato obligatorio, queda prescrita. Por último, la obediencia se elimina como un hábito que debe observarse. Lo único que impera como regla de conducta es la famosa cláusula: Faictz ce que vouldras (haz lo que quieras). Entonces desaparece por completo una vida regida por leyes, estatutos, reglas y acciones que deben cumplirse cada vez que, por ejemplo, suena la campana que llama a rezar. Incluso poco importa, si ésta toca de madrugada. Cuenta Erasmo que aborrecía este sonido, pues padecía de insomnio, y, cuando estaba obligado a despertarse a media noche para realizar las oraciones nocturnas respectivas, después ya no lograba recuperar el sueño en toda la noche.

De esta forma, encontramos en los libros de Rabelais varios episodios en donde se denuncian o ridiculizan una serie de aspectos que Erasmo anteriormente planteó en el Elogio de la locura. Entre los puntos comunes identificados en ambos autores está la sátira del clero, monjes y teólogos, pero

-Verdaderamente, mi buen hijo, ¿nos has traído hasta aquí los gavilanes de Montaigu? Nunca creí que hubieras vivido allí.

Entonces Ponócrates respondió:

- Señor no penséis que yo le haya tenido en el colegio de piojería que llaman Montaigu. Más habría querido ponerle entre los pobres de san Inocencio que entre la enorme crueldad y villanía que allí he visto; pues mucho mejor trato reciben los forzados entre los moros y los tártaros, los criminales en la cárcel, y muchísimo mejor los perros en nuestra casa, que esos desgraciados de dicho colegio, y, si yo fuera rey de París, que me lleve el diablo si no le prendía fuego para que se quemaran el rector y los regentes que consienten que ante sus ojos se cometa tanta inhumanidad. P. 123. 
también de gramáticos y profesores de filosofía. En los dos el tono jocoso siempre es el mismo y de esto están conscientes cada uno de ellos. Erasmo, por ejemplo, en la dedicatoria del Elogio a la locura, dirigida a Tomás Moro, reconoce que con este texto lo que ha hecho es mantener viva una larga tradición que viene desde Homero hasta Virgilio, Polícrates, Glauco, Sinesio, Plutarco, Apuleyo y Luciano -entre muchos otros- en la que se busca, por medio de un tono alegre, bromista y ligero hablar de algunas cosas que para otros pueden ser muy serias. En uno de los pasajes de esta dedicatoria Erasmo advierte:

[...] N'étant pas dans des circonstances favorables pour composer un ouvrage sérieux, il me prit envie de m'égayer en faisant l'Éloge de la Folie [...] Je ne doute point qu'il ne se trouve des Zoilles mal intentionnés qui crieront que ces bagatelles sont indignes d'un théologue, que ses satires sont contraires à la modéstie chrétienne; ils me reprocheront peut-être de faire renaître la malignité de l'ancienne comédie, et de mordre tout le monde, comme Lucien [...] Mais pour répondre à ceux qui pourront m'accuser d'avoir été satirique, je soutiens qu'il a toujours été permis aux gens de lettres de plaisanter sur la vie humaine, pourvu que cette plaisanterie ne dégénerât point en rage et en fureur [...] Il y a même des gens dont les scrupules sont si déplacés, qu'ils aimeraient mieux entendre des blasphèmes contre Jésus-Christ, que la plus légère plaisanterie sur les papes ou sur les grands, quoique ces plaisanteries puissent tourner à leur avantage (1941a: $1-3) .^{5}$

Con esta última opinión de Erasmo nos topamos con un problema de talla mucho mayor, porque encontraremos en el texto referido de Rabelais un episodio que, por su particular naturaleza, ha suscitado una serie de interpretaciones de diverso orden. Se trata del capítulo que narra el nacimien-

${ }^{5}$ Entonces al haber resuelto hacer algo y al no estar en circunstancias favorables para realizar una obra seria, me dieron ganas de divertirme, haciendo el Elogio de la locura $[. .$.$] No dudo que haya críticos más intencionados que gritarán que esas bagate-$ las son indignas de un teólogo, que estas sátiras son contrarias a la modestia burguesa. Tal vez me reprocharán en retomar la maldad de la comedia antigua y de morder a todos como Luciano [...] Pero, para responder a aquellos que podrán acusarme de haber sido satírico, sostengo que a la gente de letras se le ha permitido burlarse de las cosas humanas, siempre y cuando no degenere en rabia y furor. Incluso hay gente cuyos escrúpulos son tan dislocados, que preferirían escuchar blasfemias contra Jesucristo, que la broma más ligera dirigida a un pontífice o a un monarca, sobre todo si hay algo en ella que les concierne. 
to del protagonista principal del texto: Gargantúa. En este pasaje se explica su llegada al mundo de la manera más extraordinaria. El gigante sale de la oreja de su madre y de inmediato reclama gritando que quiere beber. Lo extraño de este alumbramiento podría pasar inadvertido si no viniera enseguida una reflexión que permitiera fácilmente leer este fragmento como una ofensa al dogma y como una manifestación de abierta herejía:

Je ne doubte que ne croyez asseurément ceste estrange nativité. Si ne le croyez, je ne m'en soucie, mais un homme de bien, un homme de bon sens, croit toujours ce qu'on luy dict et qu'il trouve par escript. Est-ce contre nostre loy, nostre foy, contre raison, contre la Saincte Escripture? De ma part, je ne trouve rien escript ès Bibles sainctes qui soit contre cela. Mais, si le vouloir de Dieu tel eust esté, diriezvous qu'il ne l'eust peu faire? Ha, pour grâce, ne emburelucocquez jamais vous espritz de ces vaines pensées, car je vous diz que à Dieu rien n'est impossible, et, s'il le voulait, les femmes auraient doresnavant ainsi leurs enfants par l'aureille.

Bacchus ne fut-il engendré par la cuisse de Jupiter?

Rocquetaillade nasquit-il pas du talon de sa mère?

Crocquemouche de la pantofle de sa nourrice?

Minerva nasquit-elle pas du cerveau par l'aureille de Jupiter?

Adonis par l'escorce d'un arbre de mirrhe?

Castor et Pollux de la crocque d'un æuf pont et esclous par Léda? (ed. de Jacques Boulenger 1951: 8). ${ }^{6}$

¿Qué debemos leer entre líneas en este fragmento? En primer lugar, es obvio reconocer en él una especie de desafío. Para Rabelais, cualquier relato mítico, incluyendo la Biblia, hace un llamado a la imaginación y en ellos

${ }^{6}$ Dudo que deis crédito a tan extraño parto. $Y$ si, en efecto, no lo créeis, no me importa. Mas un hombre de bien, un hombre sensato, debe creer siempre lo que le dicen y lo que ve escrito. ¿Atenta esto contra nuestra ley, nuestra fe, nuestra razón o contra la Sagrada Escritura? Por mi parte, nada hallo en la Santa Biblia que vaya en contra de ello. Pero si ésa hubiera sido la voluntad de Dios, ¿dirías acaso que no estaba en su poder al hacerlo? Por merced, no turbéis nunca vuestro entendimiento con tan vanos pensamientos, porque yo os digo, que nada es imposible para Dios y, si Él así lo quisiera, en lo sucesivo todas las mujeres parirían sus hijos por la oreja.

¿No fue Baco engendrado en el muslo de Júpiter?

¿Rocquetaillade no nació del talón de su madre?

¿No salió Croquemouche de la pantufla de su nodriza?

¿No nació Minerva de la cabeza, y por la oreja de Júpiter, y Adonis por la corteza de un árbol de mirra?

¿No nacieron Cástor y Pólux de la cáscara de un huevo puesto y empollado por Leda? P. 36. 
cabe cualquier tipo de argumento o situación que carezca de lógica y razón. Lo peligroso de este pasaje es que aquí quedan mezcladas varias cuestiones, pues se plantea en un mismo nivel el extraño nacimiento de Gargantua, los que ha recogido la mitología grecolatina, algunos inventados por Rabelais y por último el nacimiento de Jesucristo. Lo grave de todo esto es que allí mismo se señale, de manera un tanto burlona, que para Dios nada es imposible y que si él lo hubiera querido, las mujeres habrían dado a luz por la oreja. A esto se suma la idea de una leyenda popular, que recoge la creencia de que Jesucristo fue concebido por la oreja, postura condenada por la Iglesia. Lucien Febvre, en su texto Le problème de l'incroyance au XVIe siècle, advierte que la manera de imaginar el nacimiento de Cristo ha generado varias polémicas, incluso en el mismo seno de la Iglesia. Para algunos padres y doctores de la Iglesia como Irineo, Orígenes, Tertuliano, Jerónimo y Atanasio, Jesucristo nació después de nueve meses de gestación y de la manera fisiológica más normal. Muchos textos muestran su alumbramiento en medio de sangre y suciedad. Posteriormente, san Ambrosio y san Agustín se encargaron de divulgar la doctrina de un nacimiento y una crianza virginal. Dice Febvre que para éstos Cristo llegó al mundo, entrando por una puerta cerrada, sin romper ni violentar la cerradura (1968: 151).

Todas estas razones permiten reconocer que no hay ninguna intención inocente en Rabelais cuando decide plantear de esta forma el nacimiento del personaje principal del texto mencionado. Incluso más adelante, siguiendo un poco con este juego, se explica la manera en que se daba de comer al gigante recién nacido. Se señala que para satisfacer su hambre se dispusieron diecisiete mil novecientas trece vacas para atender a su crianza, advirtiendo que era imposible encontrar en todo el país alguna nodriza que pudiera alimentarlo. Rabelais aprovecha el momento y deja pasar una observación que tiñe el paisaje de herejía. Así afirma:

Combien qu'aulcuns docteurs scotistes ayent affermé que sa mère l'alaicta et qu'elle pouvait traire de ses mammelles quatorze cens deux pipes neuf potées de laict pour chascune foys, ce que n'est vraysemblable, et a esté la proposition déclairée mammallement scandaleuse, des pitoyables aureilles offensive, et sentent de loing heresie (ed. de Jacques Boulenger 1951: 47). ${ }^{7}$

${ }^{7}$ Aunque algunos doctores, discípulos de Juan Escoto, hayan afirmado que su madre le dio el pecho y que ella podía extraer de sus tetas mil cuatrocientas dos pipas y nueve jarras de leche cada vez, cosa que no parece verosímil; tal proposición ha sido declarada por la Sorbona escandalosa, ofensiva para los oídos piadosos, ya que huele de lejos a herejía. P. 32. 
Y es cierto que así como éste, hay otros episodios que huelen de lejos y de cerca a herejía, por lo que sorprende que el texto no haya sido incluido en la lista de libros prohibidos por los censores de la Iglesia, aunque figure en el catálogo de las obras revisadas por la Sorbona. Sus textos se encuentran al lado de varios autores pertenecientes a representantes o partidarios de la Reforma como Marot, Bucer y Melancton, así como Calvino y Erasmo. Sin embargo, Rabelais, al igual que el humanista holandés, mantuvo siempre, con respecto a la Reforma cismática, asociada a Lutero y Calvino, una gran distancia. Situación que no le impidió caricaturizar los errores supersticiosos de la Sorbona o de los papistas extremistas, por lo que más tarde sus enemigos reconocieron que la risa que producía era una risa sacrílega que llevaría a este autor a ser acusado más tarde de claro ejemplo de libertino.

Pasemos ahora a revisar algunos textos de Brantôme, autor que no cuenta con la fama y renombre que sí tiene Rabelais. No obstante, a lo largo de su obra, encontramos una serie de opiniones dispersas de lo que él ha visto o escuchado de otras personas que nos permiten conectarlo con cierta corriente libertina de su época. Su mirada aguda sobre algunos comportamientos de la gente de la que habla revela una ruptura con los hábitos y costumbres defendidas por la sociedad cristiana de su tiempo. Su libertinismo ya no está orientado tan directamente a la crítica del clero, a las prácticas de devoción y a cuestiones vinculadas con el dogma. Sus reflexiones están más bien centradas en problemas que tienen que ver, sí con la gente de la Iglesia, pero sobre todo con costumbres y hábitos de la sociedad en general y en particular de la clase militar y aristocrática. El retrato que hace de ésta tiene como primera intención el mostrar que un gran sector de este grupo ha desacralizado una parte de ciertas costumbres y con ello ha bañado de irrespeto algunos valores religiosos.

Uno de los estudiosos de su obra, Jean Marie Malochet (1974), prefiere hablar de libertinaje y no de libertinismo en Brantôme. La razón de la elección de este crítico está sustentada en que el libertinaje está más bien asociado al carácter licencioso en el terreno de las costumbres y hábitos, en particular los sexuales, mientras que el libertinismo se vincula por lo general a un problema de orden espiritual y el libertino por derivación será un falso creyente. Jean Claude Margolin, por su parte, advierte que el hombre que se ha liberado de la fidelidad a Dios y a la Iglesia ha traicionado con ello una causa sagrada (1974: 5). Y una vez que la moral religiosa ha sido quebrantada, por extensión, la moral familiar y social queda también dañada. Así observamos que los límites semánticos de cada uno de estos términos no logran muy bien definirse porque un libertino atenta contra la fe, pero también puede hacerlo contra la moral. El mismo Margolin reconoce 
la poca fiabilidad de los catálogos y discursos de la época para ceñir el significado de estas palabras. Pese a esta dificultad, por cuestiones de orden práctico, utilizaremos la voz que prefiere emplear Malochet para distinguir dos terrenos, que aunque estén de alguna forma comunicados, pueden analizarse como entidades que cuentan con algunos rasgos particulares y otros comunes.

Brantôme se mueve en estas dos dimensiones en textos como Les sermens et juremens espaignols y en las Rodomontades espaignoles. Veamos un fragmento del primero que ilustra parte de una nueva moral que pone en tela de juicio a la Iglesia como auténtico órgano espiritual. Este autor recoge la opinión que tenía el rey Francisco I de la gente que pertenecía al clero. Así nos la revela:

Gens inutiles, disoit-il, qui ne servoient de rien qu'à boire et manger, taverner, jouer ou faire des cordes d'arbalestes, des poches de furet à prendre des connils, de siffler des linottes. Voylà leurs exercices, et faire une desbauche que l'oisiveté leur raportait. Aussi disoit-on un proverbe commun alors: "Avare et paillard comme un preste ou un moyne" (citado en Malochet 1974: 180). ${ }^{8}$

Observamos en este fragmento una clara correspondencia con el punto de vista que Rabelais y Erasmo tenían al respecto. También, como estos partidarios y representantes del libertinismo, Brantôme plantea la costumbre en algunos de poner en duda ciertas prácticas de devoción: "Un paouvre demandant l'ausmone à un soldat pour l'honneur de Dieu, et qu'il prieroit Dieu pour luy, l'aultre mettant la main à la bource luy donna un réal: 'Tenez, dit-il, priez Dieu pour vouz, car je ne veux pas prester à usure'" (citado en Malochet 1974: 180). ${ }^{9}$ Este juicio u opinión revela un deslizamiento hacia un sistema de valores mundanos, que se separa de la moral cristiana. Lo que es interesante aquí es que Brantôme utiliza una estrategia discursiva que nos impide conocer realmente sus opiniones personales sobre los problemas que plantea. En la gran mayoría de sus textos en ningún momento utili-

${ }^{8}$ Gente inútil, decía, que no sirve para nada sino para beber y comer, ir a la taberna, jugar o hacer cuerdas de ballesta, bolsillos con trampas para atrapar conejos, y embriagarse. Éstas son sus tareas, además de entregarse a la lujuria que le propicia el ocio. Es por ello que un dicho de la época señalaba: "Avaro y lascivo como un cura o un monje".

${ }^{9}$ Un pobre al pedir limosna a un soldado por el amor de Dios, le dijo que rogaría al Señor por él, el otro sacó de su bolsillo un real y le dijo: "Tenga, pida a Dios por usted, que yo no quiero ser cómplice de usura". 
za, para exponer un juicio propio, un pronombre en primera persona, sino que se limita a escribir lo que ha escuchado o visto en los medios sociales que ha frecuentado. Su posición de testigo nos obliga a estudiarlo, no como un ejemplo de disidencia o heterodoxia, sino como un autor un tanto marginal, pero que nos resulta muy útil para reconstruir una parte de la historia de la mentalidad y de la vida cotidiana o privada de la época.

Su vocación de escritor y memorialista se debe a dos accidentes, el segundo más grave - una caída de caballo- que lo inmovilizó durante cerca de tres años, tiempo durante el cual dictó sus memorias. De ellas se desprenden cuatro textos: La Vie des Dames Ilustres, La Vie des Dames Galantes, Les Vies des Hommes Ilustres et Grands Capitanes Français y Les Vies des Hommes Ilustres et Grands Capitaines Étrangers. Si nos detuviéramos únicamente en su texto La Vie des Dames Galantes tenemos material suficiente para identificar una serie de hábitos y costumbres que exponen las particularidades de un clima social que busca deslindarse de la moral cristiana. Además, este tex to ha sido valorado por la crítica (Dictionnaire des ouvres érotiques 1971) como una obra maestra de la literatura amorosa. Este texto comprende siete discursos y en cada uno de ellos Brantôme recoge una parte de la historia de la sexualidad femenina de su tiempo. Su mérito consiste en escudriñar un terreno olvidado por los historiadores oficiales del momento. Este libro permite conocer la mejor forma de hacer cornudo al marido, las ventajas y desventajas de hacer el amor con una mujer joven, una vieja o una viuda, la importancia del tacto, la vista o el habla en cualquier acercamiento erótico, etcétera. En suma, se trata de un documento que reúne una serie de anécdotas de carácter sexual en las que Brantôme ha sido testigo, confidente o bien tal vez ha participado de ellas. Además, él mismo reconoce que con su texto no ha querido ofender ni delatar a nadie. Así nos dice:

Si je parle d'aucunes, je ne parle pas de toutes; et de ces aucunes, je n'en parle que par nom couvertz et point divulguez. Je les cache si bien qu'on ne s'en peut apercevoir, et l'escandalle n'en peut tumber sur elle que par doubte et soupçons, et non par vrayes aparances (ed. de Maurice Rat 1990: 434). ${ }^{10}$

${ }^{10}$ Solamente hablo de algunas, y no de todas; y de las que hablo, no lo hago sino por nombres falsos y sin divulgarlos. Los oculto de tal forma que no puedan imaginarlas para que sólo caiga el escándalo sobre ellas por medio de dudas y sospechas, y no por verdaderas apariencias. 
También advertirá que de todas esas mujeres que menciona en su texto: "Je ne veux point parler des personnes viles, ny de champs, ny de villes, car telle n'a point esté mon intention d'en escrire, mais des grandes, pour lesquelles ma plume volle" (ed. de Maurice Rat 1990: 424). ${ }^{11}$ Interesa detenerse en algunos pasajes, porque de sus reflexiones podemos deducir ciertas actitudes que nos hablan de algunas estrategias utilizadas para poder transgredir la moral de la época. Así nos reporta Brantôme lo que algunos opinan a propósito de las posiciones adecuadas e inadecuadas durante el acto sexual:

[...] il y a aucunes femmes qui disent qu'elles conçoivent mieux par les postures monstrueuses et surnaturelles et estranges que naturelles et communes, d'autant qu'elles y prennent plaisir davantage, et [...] quand ils s'accommodent more canino, ce qui est odieux; toutefois les femmes grosses, au moins aucunes, en usent ainsi, de peur de se gaster par le devant.

D'autres docteurs disent que quelque forme que ce soit est bonne, mais que semen ejaculetur in matricem mulieris, et quomodocumque uxor cognoscatur, si vir ejaculatur semen in matricem, non est peccatum mortale (Maurice Rat 1990: 38). ${ }^{12}$

Brantôme considera que existen muchas formas de interpretar lo que la Iglesia ordena en cuestiones de tipo sexual. Para ésta, la sexualidad sólo quedó autorizada dentro del matrimonio y con un solo fin, el de la procreación. Además condenaba cualquier acto sexual que se realizara fuera del matrimonio y detectaba como un acto pecaminoso que dentro de él hubiera expresiones de enorme pasión de la parte de la esposa así como también del marido. Sara F. Mattew Griego señala que:

${ }^{11}$ No quiero hablar de personas viles, ni del campo, ni de la ciudad, porque ésa no ha sido mi intención al escribir, sino de las grandes, para quienes mi pluma vuela.

${ }^{12}$ [...] Hay algunas mujeres que dicen que ellas conciben mejor por medio de posturas monstruosas, sobrenaturales y extrañas que por las naturales y comunes, además de que sienten mucho más placer y, $[\ldots]$ cuando se acomodan como "perritos", lo que es odioso. Sin embargo las mujeres embarazadas, al menos algunas, lo hacen así, por miedo de hacerse daño por delante.

Otros doctores dicen que cualquier forma es buena a condición que el semen sea eyaculado en la matriz de la mujer -y de cualquier manera que conozca su esposa con tal que el marido eyacule su semen en la matriz- no hay pecado mortal en ello. 
Même les positions du couple sont soumises à un strict contrôle. La position retro ou more canino (à ne pas confondre avec la "sodomie") est déclarée contre nature parce qu'elle est caractéristique de l'accouplement des animaux. Mulier super virum l'est également, puisqu'elle place la femme dans une situation active et supérieure, en contradiction avec son rôle social, passif et subordonné. Toute acrobatie érotique en dehors de la figure approuvée, la femme étendue sur les dos, l'homme la surmontant, est suspecte de privilégier le plaisir au détriment de la procréation. La seule position qui est censée favoriser l'implantation de la semence du mâle est celle associée symboliquement au geste fécondant du laboureur (1991: 81). ${ }^{13}$

Es interesante observar que tanto el discurso de los teólogos como el de los médicos - salvo notables excepciones (véase "Le discours de la médecine et de la șcience") — recomendó moderación en la expresión de la pasión así como el empleo de posturas "naturales". Sólo respetando estas normas se aseguraba una descendencia sin problemas. Los hijos que nacían con deficiencias mentales y algunas malformaciones físicas eran producto - según ellos- de excesos y manifestaciones de lujuria en el momento de la procreación. Por ello explica Brantôme la preferencia de algunos hombres de dar libre curso a su pasión con otras mujeres que no fueran sus esposas y, haciendo referencia a un personaje de la historia antigua, nos ilustra esta situación que incluso la Iglesia aceptó como lícita.

[...] l'empereur Sejanus Commodus, dit autrement Anchus Verus, lorsqu'il dit à sa femme Domitia Calvilla, qui se plaignoit à luy de quoy il portoit à des putains et courtisannes et autres ce qu'à elles appartenoit en son lict, et luy ostoit ses menues et petites pratiques: "supportez, ma femme, luy dit-il, qu'avec les autres je saoule mes desirs, d'autant que le nom de femme et de consorte est un nom de dignité et d'honneur, et non de plaisir et paillardise". Je n'ay point

${ }^{13}$ Hasta las posiciones que adoptara la pareja estaban sujetas a controles estrictos. La posición denominada retro o more canino (que no debe confundirse con la "sodomía") se declaraba contraria a la naturaleza humana porque imitaba el acoplamiento de los animales. Igualmente "antinatural" era la posición mulier super virum, en la medida en que colocaba a la mujer en una posición activa y superior a la del hombre, contraria a su rol social pasivo y subordinado. Todas las acrobacias eróticas fuera de la fórmula aprobada - la mujer boca arriba y el hombre encima de ella- se consideraban sospechosas en tanto privilegiaban el placer a expensas de la procreación. La única postura que favorecía la plantación de la semilla masculina era la que se asociaba simbólicamente al acto por el cual el labrador araba la tierra. 
encore leu ny trouvé la response que luy fit là-dessus madame sa femme l'imperatrice; mais il ne faut douter que, ne se contentant de ceste sentence dorée, elle ne luy respondit de bon cœur, et par la voix de la pluspart, voire de toutes les femmes mariées: "Fy de cet honneur, et vive le plaisiri Nous vivons mieux de l'un que de l'autre" (Maurice Rat 1990: 39-40). ${ }^{14}$

Hay que recordar que la búsqueda de una satisfacción plena durante el acto sexual quedó por mucho tiempo restringido al terreno de los hombres. Todavía en algunos manuales de confesión del siglo XVIII se seguía cuestionando el derecho al orgasmo en las mujeres. Sin embargo, médicos como Ambroise Paré y Jacques Duval (Evelyne Berriot-Salvadore 1991: 382), que no se dejaron intimidar por las prohibiciones de la moral cristiana ni por la censura de la Facultad de Medicina, insistieron en la necesidad de aconsejar al hombre sobre los modos que éste debía observar para despertar la sensualidad de su mujer. Para Paré y Liébault una de las causas más frecuentes de la esterilidad provenía del poco placer que tenía la mujer durante el acto sexual. Este tipo de discurso científico inquietó a la Iglesia, que siempre había entendido que para establecer y mantener una ética de la vida privada, como garantía del orden social, era indispensable el acuerdo de opiniones entre el médico y el confesor. Henri Corneille Agrippa en su Déclamation sur l'incertitude et vanité des sciences (Berriot-Salvadore 1991: 384) concebía a la medicina como un arte sospechoso que se prestaba muy bien para el libertinaje. En los textos de Brantôme es común observar cómo algunas mujeres aplican una serie de técnicas de carácter seudocientífico para fingir virginidad después de haberla perdido, evitar embarazos no deseados o simplemente seguir disfrutando del placer sexual después de varios meses de embarazo. Uno de los consejos o remedios consistía en el recurso a la sodomía. Veamos lo que recoge Brantôme al respecto:

Certes, de telle abomination [la sodomie] j'en ay ouy parler que plusieurs marys en sont este atteints bien au vif [...] Combien y a-il

14 [...] El emperador Sejanus Commodus, mejor conocido como Anchus Verus, cuando su mujer Domitia Calvilla se quejó de que éste llevara a su lecho a putas y cortesanas, privándola de sus pequeñas y menudas prácticas, le respondió: "Mi mujer, soporte esto, que con las otras me embriago en deseos, ya que el nombre de mujer y de consorte es un nombre digno y de honor, y no para el placer y la lascivia". No he leído aún, ni encontrado la respuesta que al respecto le dio su mujer, la emperatriz. Pero no dudo, que al no contentarse con esta sentencia dorada le respondiera de todo corazón y en defensa de la mayoría, incluso de todas las mujeres casadas: " Nada de este honor y que viva el placeri Vivimos mejor con uno que con el otro". 
de femmes au monde que, si elles estoient visitées par des sagesfemmes et medecins et chirurgiens experts, ne se trouveroyent non plus pucelles par le derriere que par le devant, et qui feroyent le procez à leurs marys à l'instant; lesquelles le dissimulent et ne l'osent descouvir, de peur d'escandaliser et elles et leurs marys, ou, possible, qu'elles y prennent quelque plaisir plus grand que nous ne pouvons penser [...] [la sodomie est permise] aux femmes grosses, et aussi à celles qui ont l'haleine forte et puante, tant de la bouche que du nez (ed. de Maurice Rat 1990: 112-113). ${ }^{15}$

Brantôme insiste en este tema y expone cómo la sodomía fue motivo de queja de varias mujeres que acusaban a sus maridos de esta predilección "perversa". Pero al mismo tiempo, también era un arma eficaz utilizada por éstas para cometer adulterio, protegiéndose de una posible queja del esposo si fueran descubiertas, pues podrían delatarlo ante las autoridades correspondientes de abusar de ellas con prácticas ilícitas como era la sodomía. Además, también señala que esta práctica "detestable y herética" (ed. de Maurice Rat 1990: 112) era común entre los judíos y los malos rabinos. Así nos relata la historia de dos mujeres que al asistir a una sinagoga para quejarse de haber tenido con sus maridos conocimiento de la sodomía, pues habían sido forzadas a ello, los rabinos les habían respondido que un marido era el dueño de su mujer y que podía hacer con ella lo que quisiera. Para convencerlas estos rabinos usaron una comparación, diciéndoles que cuando uno compra un pescado tiene todo el derecho de comerlo ya sea por delante como por detrás. Auxiliándose de una serie de anécdotas, Brantôme revisa cada una de las prácticas prohibidas por teólogos y algunos médicos por considerarlas pecaminosas o antinaturales. Entre éstas están los juegos sexuales entre mujeres - "la fricarelle"- y el uso de penes artificiales - "godémichés"-, la masturbación, el coitus interruptus y la bestialidad, entre otros, pues se trataba de pecados sexuales que quebrantaban la necesidad de reproducción en nombre de placeres llamados perversos.

Un último aspecto que podríamos mencionar aquí y que nos permitiría relacionar a Brantôme con Rabelais y por extensión con Erasmo es su posi-

${ }^{15}$ Es cierto, de tal abominación [la sodomía] he oído decir que algunos maridos son muy afectos a ella [...] De cuántas mujeres en el mundo, si fueran revisadas por comadronas, médicos y cirujanos expertos, no se encontraría ninguna virgen ni por delante ni por detrás, e inmediatamente iniciarían un proceso en contra de sus maridos; ellas lo disimulan y no se atreven a decirlo, por miedo a escandalizar a otros y también a sus maridos, pues tienen más placer de lo que podemos imaginar, [la sodomía está autorizada] a las mujeres embarazadas y a las que tienen un fuerte aliento apestoso ya sea de la boca como de la nariz. 
ción frente al encierro. En el séptimo y último discurso del texto en el que nos hemos detenido - La Vie des Dames Galantes-este autor hace resaltar las limitaciones y crueldades de la vida de los conventos. En un pasaje de este discurso nos dice:

Et, pour dire vray, il faut laisser et ordonner telles receptes austeres et froides aux paouvres relligieuses, lesquelles, encores qu'elles jusnent et macerent leurs corps, si sont-elles souvant assaillies, les paouvrettes, de tentations de la chair; et, si elles avoient liberté (au moins aucunes), se voudroient raffraischir comme les mondaines. [...] Quelle repentance! et, quand une fois, elles y ont esté proffesses, au moins les belles, je dis aucunes, je croy qu'elles vivent plus de repentance que de viandes corporelles ny spirituelles. [...] Laissons ces paouvres recluses, que, ma foy, quand elles sont là une fois renfermées, elles endurent assez de mal; ainsi dist une fois une dame s'Espaigne, voyant mettre en relligion une fort belle et honneste damoyselle: "O paouvre miserable, en quoy avez-vous tant peché, que si prestement vous venez à pénitence, et estes mise toute vive en sepulture!" (Maurice Rat 1990: 412-413). ${ }^{16}$

La gran mayoría de los escritores vinculados con cualquier tipo de libertinismo o libertinaje denunciarán la inutilidad del encierro, pues genera corrupción en las costumbres. Hemos visto que Rabelais lo apunta en las observaciones que hace sobre el Colegio de Montaigu y en el pasaje de la abadía de Thélème donde se dice que jamás se levantaría algún muro en dicha construcción, porque para Rabelais: "où mur y a et davant et derrière, y a force murmur, envie et conspiration mutue" (ed. de Jacques Boulenger 1951: 170). ${ }^{17}$ Erasmo, por su parte, en sus coloquios "La virgen que odia el matrimonio" y "La virgen arrepentida" (1991b: 680-690) maldice a aque-

\footnotetext{
${ }^{16} \mathrm{~A}$ decir verdad, hay que dejar de ordenar tales recetas austeras y frías a las pobres religiosas, las cuales, además de ayunar y macerar sus cuerpos, a menudo son asaltadas las pobrecillas por tentaciones de la carne: pero, si gozaran de libertad (al menos algunas) desearían satisfacerse como lo hacen las mundanas. [...] Una vez que han hecho sus votos, al menos las hermosas - hablo de algunas - creo que viven más de arrepentimiento que de carne corporal y espiritual. [...] Dejemos a esas pobres reclusas, que palabra de honor, estando allí encerradas, soportan grandes males; así, una vez una dama española, al ver hacer sus votos a una hermosa y honesta señorita le dijo: "O pobre miserable, y en que pecastes, que tan presto cumples con tu penitencia y quedas sepultada en vida".

${ }^{17}$ Rabelais, Gargantua. Donde hay muros, hay, delante y detrás de ellos, mucha murmuración, envidia e intrigas mutuas. P. 163.
} 
llos que atraen adolescentes y jovencitas a ingresar a monasterios y conventos, aprovechándose de su inocencia y buena fe. Así hace resaltar la cantidad de vicios y hábitos insanos que allí imperan, pero sobre todo se rebela contra la tendencia de hacer de éstos esclavos de sus cuerpos pero por encima de todo de su mente y espíritu.

En un momento dijimos que en los textos de Erasmo se encuentra la materia prima de muchas preocupaciones que denunciarán más tarde los partidarios del libertinismo. Tenemos aquí un claro ejemplo, el encierro, que no sólo aparece identificado como una práctica abominable en Rabelais y Brantôme. Basta rastrear algunos textos posteriores que lo hacen con un tono, tal vez, más amargo y mucho más sombrío, como es el caso de Diderot, quien en su obra La Religieuse él mismo afirma que nunca antes se había escrito una espantosa sátira de los conventos como él lo ha hecho. Veamos lo que al respecto nos dice:

Voilà l'effet de la retraite. L'homme est né pour la société. Séparezle, isolez-le, ses idées se désuniront, son caractère se tournera, mille affections ridicules s'élèveront dans son coeur, des pensées extravagantes germeront dans son esprit, comme les ronces dans une terre sauvage. Placez un homme dans une forêt, il y deviendra féroce; dans un cloître, où l'idée de nécessité se joint à celle de servitude, c'est pis encore, on sort d'une forêt, on est esclave dans un cloître. Il faut peut-être plus de force d'âme encore pour résister à la solitude qu'à la misère; la misère avilit, la retraite déprave (ed. de Robert Mauzi 1972: 198). ${ }^{18}$

Sin embargo, en esta obra hay un cambio radical en el tono, desaparece la burla jocosa e irónica que ha sido identificada como sacrílega y eminentemente herética. Es por todo esto que no debe negársele al pensador holandés el hecho de que haya sido él quien abrió el camino a todos aquellos a quienes se les ha impuesto el atributo de escritor "libertino", aspecto que hemos querido ilustrar en estas breves líneas.

${ }^{18}$ Éstos son los efectos del encierro. El hombre ha nacido para vivir en sociedad. Sepárelo, aíslelo y sus ideas se desintegrarán, su carácter se transtornará y mil dolencias ridículas aquejarán su corazón, opiniones descabelladas germinarán en su mente, como juncos en una tierra salvaje. Coloque al hombre en una selva y se volverá feroz; en un claustro, donde la idea de necesidad se suma a la de servidumbre, será todavía peor. Se puede escapar de una selva, pero en un claustro se es esclavo. Quizá hace falta más entereza para resistir a la soledad que a la miseria. La miseria envilece, el encierro deprava. 


\section{Obras citadas}

Berriot-Salvadore, Evelyne. 1991. "Le discours de la médecine et de la science". Histoire des femmes en Occident, bajo la dirección de Georges Duby y Michelle Perrot. París: Plon.

Bourdeille, Pierre de (abad de Brantôme). 1990. Les dames galantes. Ed. de Maurice Rat. París: Librairie Génerale Française.

Dictionnaire des auvres érotiques. 1971. Prefacio de Pascal Pía. París: Mercure de France.

Erasme. 1941a. Éloge de la Folie. París: Cluny. 1991b. Euvres choisies. París: Librairie Générale Française.

Febvre, Lucien. 1968. Le problème de l'incroyance au XVIe siècle. La religion de Rabelais. París: Albin Michel.

Lauvergnat-Garnière, C. 1978. "Rabelais lecteur de Lucien de Samosate". Cahiers de l'Association Internationale des Études françaises, núm. 30. París.

Malochet, Jean-Marie. 1974. "Quelques aspects du libertinage au XVIe siècle d'après Brantôme". Aspects du libertinisme au XVle siècle. París: Vrin.

Margolin, Jean-Claude. 1974. "Libertins, libertisme et libertinage au XVIe siècle". Aspects du libertinisme au XVIe siècle. París: Vrin.

Matthews Griego, Sara. 1991. "Corps, apparence et sexualité". Histoire des femmes en Occident, bajo la dirección de Georges Duby y Michelle Perrot. París: Plon.

Rabelais, François. 1951. Gargantua. Ed. de Jacques Boulenger. París: La Pléiade.

1993. Gargantúa. Trad. de Juan G. de Luaces. Barcelona: Plaza \& Janes.

Screech, Michael. 1992. Rabelais. París: Gallimard. 